\title{
Relationship between apical membrane elasticity and stress fiber organization in fibroblasts analyzed by fluorescence and atomuc force microscopy
}

\section{AUTHOR(S):}

Kidoaki, Satoru; Matsuda, Takehisa; Yoshikawa, Kenichi

\section{CITATION:}

Kidoaki, Satoru ...[et al]. Relationship between apical membrane elasticity and stress fiber organization in fibroblasts analyzed by fluorescence and atomuc force microscopy. Biomechanics and Modeling in Mechanobiology 2006, 5(4): 263-272

\section{ISSUE DATE:}

2006-11

URL:

http://hdl.handle.net/2433/49160

\section{RIGHT:}

Copyright (2006) by the Springer-Verlag Berlin Heidelberg. The original publication is available at www.springerlink.com.; この論文は出版社版でありません。引用の際には出 版社版をご確認ご利用ください。; This is not the published version. Please cite only the published version. 


\title{
Relationship between apical membrane elasticity and stress fiber organization in fibroblasts analyzed by fluorescence and atomic force microscopy
}

\author{
Satoru Kidoaki ${ }^{1 *}$, Takehisa Matsuda ${ }^{1}$, Kenichi Yoshikawa $^{2}$
}

1: Division of Biomedical Engineering, Graduate School of Medicine, Kyushu University, Fukuoka 812-8582, Japan

2: Department of Physics, Graduate School of Science, Kyoto University, Kyoto 6068502, Japan

Running title: Relation between cellular microelasticity and structures of stress fibers.

Key words: cell mechanics, microelesticity, force measurement, apical stress fiber, twodimensional Fourier analysis

*To whom correspondence should be addressed.

E-mail: kidoaki@medeng.med.kyushu-u.ac.jp

Tel: +81-92-642-6942, Fax: +81-92-642-6212 


\begin{abstract}
To investigate the relationship between cellular microelasticity and the structural features of cytoskeletons (CSKs), a microindentation test for apical cell membranes and observation of the spatio-distribution of actin CSKs of fibroblasts were performed by fluorescence and atomic force microscopy (FM/AFM). The indentation depths of apical cell membranes were measured from AFM force-indentation $(f-i)$ curves under equal final loads and were mapped two-dimensionally to show the relative distribution of local microelasticity on cell membranes. Intracellular spatial distribution of actin CSKs was visualized fluorescently by high Z-resolution cross-sectional observation of a cell on which indentation mapping analysis had been performed in advance. Structural features of stress fibers (SFs) were observed as three typical patterns of dense-SF, sparse-SF and sparser-SF cell groups, which were quantitated using the degree of orientation in apical SFs (ASFs) that had been defined using two-dimensional Fourier analysis. In indentation depth maps, the upper nuclear region was markedly softer than the pseudopodium region. The mean indentation depth of the upper nuclear region decreased with increased SF density in whole cells and the degree of orientation of ASF, although the pseudopodium region did not exhibit such a trend. The apical membrane of adhered cells was found to tend to stiffen with the increase in both density and degree of orientation of SFs.
\end{abstract}




\section{Introduction}

Cell shape is known be closely related with cellular functions such as proliferation, differentiation and metabolic activity [von der Mark et al. 1977; Folkman and Moscona 1978; Stein and Bronner 1989]. Understanding the mechanisms that determine cell shape in the extracellular matrix and on an artificial substrate is essential for cellular biomechanics and bioengineering. Three principal aspects that dynamically interact and cooperatively contribute to cell mechanics have been examined from a mechanical and structural viewpoint: adhesion mechanics to the extracellular milieu, the organization features of cystoskeletons (CSKs), and cell-membrane deformation properties.

Regarding adhesion mechanics, both the focal adhesion (FA) complex of integrin and receptor adhesion proteins such as fibronectin, and stress fibers (SF) connected to the FA complex generate vertical adhesion forces and horizontal traction forces in the adhesion interface. The manner of distribution of the FA complex and mechanical properties of the FA-SF conjugated systems play a critical role in determining the shape of the adhesion interface and total adhesion strength [Zhu et al. 2000]. In the CSK mechanics aspect, formation, structure and changes in three types of CSKs, including microfilaments (MFs), intermediate filaments (IFs) and microtubules (MTs), control the cell shape. The cellular tensegrity model proposes balances between the tensional force generated by MFs and the compression force by MTs, and between substrate traction forces and MF contractions determine the cell shape [Ingber and Folkman 1989; Wang et al. 2001; Ingber 2003]. The membrane mechanics aspect is controlled by mechanical properties of the assembled structure of lipid molecules, membrane proteins and 
steroids, and of cortical lining actin meshworks [Evans and Yeung 1989; Oster 1989]. Both the internal pressure and inherent membrane tension of the cell generated by such structural factors determine cell membrane deformation.

In principle, cell behaviors that are related to the cell shape, e.g., adhesion, spreading and migration, are controlled through the interplay among or integration of the above-mentioned mechanical factors as well as biochemical processes. Determination of a quantitative correlation among them is essential for understanding cell mechanics. For characterizing such interrelationships, several methodologies were developed to determine the mechanical properties of adhered cells, which include cell poking [Petersen et al. 1982], traction force microscopy [Dembo and Wang 1999; Lo et al. 2000; Munevar et al. 2001; Wang et al. 2002], magnetic twisting cytometry [Wang et al. 1993; Wang and Ingber 1995], and atomic force microscopy (AFM) [Henderson et al. 1992; Kasas et al. 1993; Chang et al. 1993; Hoh and Schoenenberger 1994; Shroff et al. 1995; Rotsh and Radmacher 2000]. Of these approaches, AFM force measurement technique has become a powerful tool in the last decade because it directly measures the relationship between applied force (stress) and deformation (strain) of a cell at the nanoscale level. Although AFM provides mechanical information about the cell surface and subsurface region, it cannot probe intracellular CSK structures. Quantitative understanding of the effect of intracellular architectures of CSKs on cell elasticity has been insufficient so far. The AFM force measurement technique coupled with simultaneous fluorescence microscopic observation of CSKs may determine the relationship between cell elasticity and structural features of CSKs in an identical cell. 
Especially, architectural contributions from CSKs, such as orientation of CSK fibers, may be related to cell elasticity, which is expected to be analyzed using the combined methodology.

In the present study, fluorescence and atomic force microscopy (FM/AFM) [Yoshinaga et al. 2002] was employed to investigate the relationship between cell elasticity and structural features of actin CSKs. The relative microelasticity distribution of the apical cell membranes of cultured fibroblasts was analyzed using twodimensional mapping of the indentation depth under equal final loads. The intracellular spatial distribution of actin CSKs was investigated using high Z-resolution crosssectional observation with a high-aperture oil-immersion 100× objective lens (NA; 1.35, focal depth; ca. $230 \mathrm{~nm}$ ). Mean indentation depth as the relative index of cellular elasticity was compared with the structural features of SFs characterized by their density and orientation. Statistical comparison indicated that apical cell membranes are stiffened by the increase in both SF density and the degree of SF orientation.

\section{Materials \& Methods}

\section{Cell preparation}

A mouse fibroblast cell line (3T3-Swiss albino) purchased from Dainippon Pharmaceutical Co. Ltd. (Osaka, Japan) was cultured in Dulbecco's modified Eagle's medium (DMEM; Gibco BRL, Grand Island, N.Y., USA) supplemented with $10 \%$ fetal bovine serum (FBS; Gibco BRL), 3.5 g / 1 glucose, 2 mM L-glutamine, 100 units / ml penicillin, and $100 \mu \mathrm{g} / \mu \mathrm{l}$ streptomycin. The cells were maintained on tissue culture 
polystyrene dishes at $37^{\circ} \mathrm{C}$ under $5 \% \mathrm{CO}_{2}$ in a humidified incubator. Prior to force volume (FV) measurement by AFM, 80-90\% confluent cells were trypsinized and harvested as a suspension. Then, $1 \times 10^{4}$ cells were seeded in $35-\mathrm{mm}-\phi$ glass-based dishes (Iwaki Glass Co. Ltd., Japan) pretreated with 100\% FBS, and incubated between $24 \mathrm{~h}$ and $48 \mathrm{~h}$. Just before measurements, a serum-free Leibowitz's L-15 medium (Gibco BRL) medium was substituted for DMEM to maintain a constant $\mathrm{pH}$ during measurement without a $5 \% \mathrm{CO}_{2}$ atmosphere.

\section{Indentation depth mapping by AFM force volume measurement}

Indentation depth mapping of the apical cell membranes was performed by the following three steps: (1) $f$ - $i$ curves were measured for lattice points of $13 \times 13$ every 4 $\mu \mathrm{m}$ (169 points, $48 \times 48 \mu \mathrm{m}$ area) of a cell membrane (FV measurement) [Radmacher et al. 1996] under equal final loads of $1.5 \mathrm{nN}$, using FM/AFM (NVB100; Olympus Optical Co. Ltd., Tokyo, Japan; AFM controller \& software: Nanoscope IIIa, Digital Instruments, CA, USA) with a commercial silicone-nitride cantilever with a halfpyramidal tip and nominal spring constant of $0.03 \mathrm{~N} / \mathrm{m}$ (Bio-lever; Olympus Optical Co. Ltd.). Cells were incubated at $35-37^{\circ} \mathrm{C}$ in a temperature-controlled open chamber (MATS-CO2CHK; Tokai HIT Co. Ltd., Shizuoka, Japan) during FV measurement. The resolution and the scan area were set to complete the FV measurement within 30 min to avoid the effects of cell movement and changes in osmotic pressure that typically result of water evaporation from the medium. During measurement, the relative trigger mode was employed to keep the final load constant. The Z-center position of the scanning head was optimized dynamically using a stepping motor. The force was loaded through 
the tip-approaching movement with a constant rate and was increased continuously to the maximum trigger value. Then the force was unloaded through the tip-retracting movement with a constant rate. The rate of the repeated motion of tip-approaching and retracting in the Z-direction was set at as $1.5 \mathrm{~Hz}(7.5 \mu \mathrm{m} / \mathrm{s})$ to minimize the viscosity effect at around $30^{\circ} \mathrm{C}$ [Hassan et al. 1998]. (2) The indentation depths were measured from the traveling distances of the tip in the tip-sample contact region for each $f-i$ curve. The initial contact position was defined as the point at which the force increment in the tip-approaching process becomes markedly higher than the noise fluctuation level in the tip-sample noncontact region. (3) Finally, the measured indentation depths were plotted as a gray-scale image of $65 \times 65$ pixels, increasing the pixel numbers of raw data $(13 \times$ 13 pixels) through bilinear interpolation using the NIH image ver.1.62 software, which produced the indentation depth map in the FV area. Such an increase of pixels was applied to modify the unnatural description of discrete change in indentation depth around the boundary between two neighboring FV areas of $4 \times 4 \mu \mathrm{m}$.

\section{Actin observation}

Actins were visualized fluorescently. Immediately after FV measurement, the medium was removed and the cells were fixed in $10 \%$ formalin in phosphate buffered saline (PBS) for $10 \mathrm{~min}$, rinsed three times with PBS, permeabilized in $0.5 \%$ Triton $\mathrm{X}$ 100 for $5 \mathrm{~min}$, and rinsed again three times with PBS. Then, rhodamine-phalloidin (Molecular Probes Inc., Eugene, OR) was added at $0.07 \mu \mathrm{M}$ in PBS and incubated for 1 $\mathrm{h}$ at room temperature. After incubation, excess dye was removed by rinsing three times with PBS. The spatial distribution of actins inside a cell was observed using a 
fluorescence microscope with an ultraweak-light-detecting CCD camera and a videoenhancing unit (EB-CCD and Argus 50; Hamamatsu Photonics KK) connected to the FM/AFM system, and with an oil-immersion 100× objective lens (UpalnApo; Olympus Optical Co. Ltd.) with a high $\mathrm{Z}$ resolution (NA; 1.35, focal depth; ca. $230 \mathrm{~nm}$ ), while changing the focal plane manually by approximately $1 \mu \mathrm{m}$ increments from the basal side to the apical side of the cell using an objective handle.

\section{Two-dimensional Fourier analysis of apical stress fiber patterns}

The degree of orientation of the apical stress fiber patterns (ASFs) was quantitated using two-dimensional Fourier analysis [Wood 1990]. The orientation distribution function (ODF) of the two-dimensional power spectra of the fluorescence images of ASFs was calculated for 20 cells as follows: First, the power spectra images were produced through discrete Fast Fourier Transform (FFT) using NIH image ver.1.62 software for 8-bit gray-scale fluorescence microscopic images of actins in the nuclear region of a cell, which was clipped into a $128 \times 128$ pixel area and pretreated with the Hanning window function. Windowing was employed to reduce the contribution of an artificial frequency arising from the edge discontinuity [Pourdeyhimi 1997]. Next, the images of the windowed FFT power spectra were exported as text data of the twodimensional array of powers. Finally, ODF $\mathrm{P}(\theta)$ were calculated from power data using Visual Basic and Excel 2001 software (Microsoft Corp.) according to [Wood 1990],

$$
\begin{aligned}
& P\left(\theta_{1}, \theta_{2}\right)=\sum_{u, v} P(u, v) / \frac{1}{2} N^{2}\left(\theta_{2}-\theta_{1}\right) \\
& \theta_{1} \leq \tan ^{-1}(u / v)<\theta_{2}
\end{aligned}
$$




$$
\begin{aligned}
& 0<u \leq N-1 \\
& 0<v \leq N-1,
\end{aligned}
$$

where $\mathrm{P}(\mathrm{u}, \mathrm{v})$ is the power at the frequency domain $(\mathrm{u}, \mathrm{v})$, and $\mathrm{u}, \mathrm{v}$ and $\mathrm{N}$ are integers. In addition, $\theta_{1}$ and $\theta_{2}$ are the angles of the two radii that form the sector. At the limit, as $\theta_{2}$ $\rightarrow \theta_{1}, \mathrm{P}\left(\theta_{1}, \theta_{2}\right)$ becomes the ODF function $\mathrm{P}(\theta)$. In this study, the limit angle $\left(\theta_{2}-\theta_{1}\right)$ and radius of the sector for averaging the power distribution were set respectively at $5^{\circ}$ and 32 pixels in the frequency domain.

\section{Statistical analysis}

Comparison of the indentation depths at the upper nuclear region and pseudopodium region of 20 cells among three cell groups classified by SF density and orientation was performed using both one-way factorial ANOVA and Ryan's multiple comparison. Values of $p<0.05$ were considered statistically significant.

\section{Results}

Indentation depth mapping and observation of intracellular spatial distribution of actin cytoskeletons

Indentation depths in apical cell membranes of cultured fibroblasts were measured using AFM under the equal final load, and two-dimensionally mapped as a gray scale contour graph to visualize the relative microelasticity distribution on the cell membrane. Subsequently, intracellular spatial distribution of actin CSKs in the same cell was observed fluorescently in high Z-resolution cross-sectional images obtained at $1-\mu \mathrm{m}$ intervals. Within the 20 cells for which these coupled examinations were performed, 
three representative observations for cells that exhibited different features in indentation mapping and structural features of actin CSKs are shown in Figs. 1-3.

For the cell in Fig. 1a, indentation depths measured under the load of $1.5 \mathrm{nN}$ for 13 $\times 13$ lattice points in the white dotted square area were mapped as in Fig. 1b, which varied between approx. 150 and $1000 \mathrm{~nm}$. Here the relatively high load of $1.5 \mathrm{nN}$ was adopted to evaluate not only the contribution of deformation of cortical actin network, but also of structural changes of SFs to the elasticity of apical cell membrane. Under the $1.5 \mathrm{nN}$ load, no measured $f-i$ curves exhibited a straight profile in the tip-sample contact region, even in the pseudopodium region (data not shown), which suggests that the AFM probe tip does not reach to the substrate position and that full compression of pseudopodium is avoided in the indentation process. In the maps, the darker area indicates the deeper indented (i.e. softer) area, and mean indentation depth and its standard deviation in the upper nuclear region and pseudopodium region (including both lamellipodium and filopodium) were determined respectively, as $470 \pm 170 \mathrm{~nm}$ and 300 $\pm 140 \mathrm{~nm}$, suggesting that the former is softer than the latter. In the observation of the intracellular spatial distribution of actin CSKs, as the focal plane was moved from the basal side towards the apical side of the cell, many thick well-developed SFs were observed near the basal side (basal stress fibers, BSFs, Fig. 1c), in both sides of the nucleus (Figs. 1d and 1e), and above the nucleus (apical stress fibers, ASFs, Figs. 1f and 1g). The ASFs are attached closely to the apical cell membranes by adhesive plaques [Osborn et al. 1978; White and Fujiwara 1986; Katoh et al. 1995; Katoh et al. 1996]. Therefore, the $\mathrm{Z}$ position of the highest ASF (Fig. 1g) approximately marks the top 
region of the cell. The total Z-movement distance of the focal plane from the BSF observation position to the highest ASF observation position shows that the approximate cell height in Fig. 1 was $3-4 \mu \mathrm{m}$, which suggests that the indentation depths measured in the mapping were between $10-15 \%$ of the cell height. The group of cells represented in Fig. 1 that contains many well-developed SFs in the whole cell is denoted as the “dense SF" group below.

For the cell in Fig. 2a, the upper nuclear and pseudopodium regions exhibited mean indentation depths of $770 \pm 190 \mathrm{~nm}$ and $350 \pm 100 \mathrm{~nm}$ (Fig. 2b), respectively, suggesting that the former is much softer than the latter. The upper nuclear region of the cell in Fig. 2 was markedly softer than that of the cell shown in Fig. 1. In the entire region ranging from the basal side to apical side of the cell, SFs were observed to be sparse and dispersed granular aggregates of actins coexisted with the sparse SFs (Figs. 2c-2h). This type of cell group that exhibited the coexistence of sparse BSFs, sparse ASFs, and the granular aggregates of actins was denoted as the "sparse SF" group. The cell height evaluated from Figs. 2c-2h was approximately 5-6 $\mu \mathrm{m}$.

The cell in Fig. 3a exhibited considerably large indentation depths that ranged between 150 and $1800 \mathrm{~nm}$ (Fig. 3b). The mean indentation depths of the upper nuclear region and pseudopodium region were, respectively, $1300 \pm 130 \mathrm{~nm}$ and $450 \pm 120 \mathrm{~nm}$. Compared with the cells depicted in Figs. 1 and 2, both the upper nuclear and pseudopodium regions were much softer. The coexistence of sparse BSF and many granular aggregates of actins was observed near the basal side (Fig. 3c), whereas only the granular aggregates and no SFs were observed around the nucleus (Figs. 3e and $3 \mathrm{f}$ ) 
or above the nucleus (Figs. $3 g$ and $3 h$ ). This type of cell group that exhibits the feature of sparse BSF and no ASF is denoted as "sparser SF" group. The cell height was evaluated as approximately $10-12 \mu \mathrm{m}$ (Figs. 3c-3h are shown at 2- $\mu \mathrm{m}$-intervals).

\section{Comparison between mean indentation depth and structural feature of SFs}

Because the indentation depths measured under equal final load are normalized values that thereby reflect the relative local Young's modulus (see Discussion), the indentation depth mapping not only provides information on the microelasticity distribution in a single cell; it also enables the quantitative comparison of the microelasticities of many cells. Figure 4 shows the mean indentation depth for the upper nuclear region (Fig. 4a) and the pseudopodium region (Fig. 4b) on each of the measured 20 cells, which were classified into one of the three cell groups of dense SF, sparse SF, or sparser SF. For the upper nuclear region, the indentation depths varied from 150-750 $\mathrm{nm}$ in the dense SF group, 450-1300 nm in the sparse SF group, and 600-1600 $\mathrm{nm}$ in the sparser SF group. The indentation depths tended to increase in the order of dense SF, sparse SF, and sparser SF groups: the order of decreasing SF density. On the other hand, for the pseudopodium region, the indentation depths were distributed in a similar range of $100-600 \mathrm{~nm}$ among the three cell groups, suggesting that the elasticity of the pseudopodium region does not exhibit clear dependence on the SF density. The total mean and standard deviations of the indentation depths in each cell group are shown in Fig. 5. It has been confirmed statistically that the indentation depths in the upper nuclear region decreased: the membrane stiffened concomitant with the increasing SF density. In the pseudopodium region, irrespective of the SF density, the indentation depths were 
markedly less than those in the upper nuclear region, which suggests that the former is stiffer than the latter in the cultured cells.

As the next step, the relationship between the mean indentation depth and SF orientation was investigated quantitatively using the degree of fiber orientation evaluated through two-dimensional Fourier analyses of the SF distribution patterns. Fourier methods are useful for extracting orientation information quantitatively by transforming a gray-scale image into a frequency image. Spatial frequencies in the perpendicular direction will appear to be high if any fibrous components are oriented predominantly in a given direction [Wood 1990; Pourdeyhimi 1997]. The degree of orientation can be reflected in the power contribution in the spatial frequency domain. In this study, ASF distribution patterns were chosen especially to be analyzed as representative information of SF orientation in a cell.

The left panels in Fig. 6 exemplify typical fluorescence images of ASF with different degrees of development. For each image, Fourier power spectra and orientation distribution function (ODF) were obtained as shown respectively in the middle and right panels. In the power spectra of the dense ASF image (Figs. 6a and 6b), a characteristic direction with higher power than the other directions appeared, and the higher power region spread widely to high-frequency domains. For the sparse ASF images (Figs. 6c and 6d), although both the characteristically oriented power distribution and the isotropic broad power distribution were observed, the range of the concentrated power region from the center is rather narrower than the dense ASF image. In the case of no ASF (Figs. 6e and 6f), no characteristic direction was observed and 
only an isotropic broad power distribution appeared. Both the direction of orientation and the mean power level in that direction were measurable from the ODF. Based on these measurements, we defined the degree of orientation as the difference between the maximum and the minimum power levels in the peak of ODF. Figure 7 shows a plot of mean indentation depths versus the degree of orientation of ASF. The degree of orientation of ASF was varied less than 11 (arbitrary unit) for the sparser SF group, 11-17 for the sparse SF group, and 18-31 for the dense SF group, indicating that the increase in ASF orientation tends to be accompanied by the increase in SF density in a whole cell. The correlation coefficient for the mean indentation depth and the degree of orientation was -0.77 , suggesting a significant correlation between them: indentation depths tended to decrease; i.e., the apical cell membrane was stiffened, with increases in both SF density in whole cells and the degree of orientation of ASFs.

\section{Discussion}

In general, the shape and motility of adherent cells are determined by the dynamic balances of the following three principal aspects of mechanical and/or biochemical factors belonging to different structural divisions in an adhered state: (1) Basal membranes, adhesion mechanics including adhesion and traction forces generated by the adhesion machineries on a substrate; (2) inside a cell, the contributions of CSKs and cytosol that include the polymerization dynamics of CSK elements (dynamic instability), mechanical property of CSK filaments and their bundling, and viscoelastic property of CSK matrix in cytosol; and (3) the apical membrane, elasticity and tension that are 
regulated by the lateral assembly force of membrane molecules and the mechanical property of the lining cortical actin network, etc. Understanding quantitative correlations among these aspects is an important issue of cell mechanics. In this study, to gain some insight into such interrelationships, both the cellular microelasticity and the structural features of actin CSKs (SF density and orientation) were characterized quantitatively in identical cells and compared to one another.

For analyses of cellular microelasticity, the indentation depth of the apical cell membrane was measured using AFM under equal final load, which provided the relative index for microelasticity, as described in the following theoretical basis [Hassan et al., 1998]. According to the Hertz model [Hertz 1881; Sneddon 1965], the relationship between force and indentation depth in the case of using a conical shaped indenter such as AFM probe tip, is written as

$$
F=\frac{2 \tan (\alpha)}{\pi} \frac{E}{1-\mu^{2}} \delta^{2}
$$

where $\alpha, \mathrm{E}, \mu$, and $\delta$ respectively represent the semivertical angle of the conical tip, Young's modulus of the sample surface, the Poisson ratio, and the indentation depth. When the $f-i$ curves are measured at different positions in a single cell or in different cells under equal load, Eq. 1 is reduced to

$$
\frac{E_{1}}{E_{2}}=\left(\frac{\delta_{2}}{\delta_{1}}\right)^{2},
$$

where the suffixes denote points 1 and 2. Equation 6 suggests that the squared ratio of indentation depths in different positions is inversely proportional to the ratio of elastic 
moduli, which is independent of the conditions of the tip-sample contact area, Poisson's ratio, cantilever's spring constant, and the semivertical angle. Consequently, the twodimensional relative microelasticity distribution in a single cell and elasticity differences between different cells can be analyzed simply through measuring, plotting and comparing only the indentation depths under equal load. Based on Eq. 6, Young's moduli of the upper nuclear region in sparser SF, sparse SF and dense SF cells are evaluated respectively as approximately 0.07 -fold, 0.13 -fold and 0.36 -fold of that in the pseudopodium region of the cells (see Fig. 5), which suggests that the upper nuclear region is 3-fold to 14 -fold softer than the pseudopodium region and tends to be stiffened with increasing SF density and orientation. Such a tendency that the nuclear region is markedly softer than the peripheral one with more microfilaments well corresponds with that described in previous works [Shroff et al. 1995, Rotsch and Radmacher 2000]. On the other hand, the elasticity of the pseudopodium region exhibited no marked dependency on the SF density (see Fig. 4b) in the present result, though the substrate effect has been carefully avoided in force-indentation measurements. From the experiment of drug-induced disruption of microfilaments such as by cytochalasin $\mathrm{B}$, it has been reported that all regions of the cell are softened except for the nuclear region [Petersen et al. 1982]. Such the difference of elasticity response of the peripheral region between the present result and the literature are attributable to the difference in the structure of cortical actin network, which was retained in our study, but disrupted in the experiment using cytochalasin B.

Considering the reason for the tendency mentioned above, it is noteworthy that four 
classes of mechanistic factors act in the cortical region of apical cell membranes: (1) elasticity induced by the bending of the membrane itself [Oster 1989], (2) elasticity induced by the bending and/or entropic writhing of the cortical lining actin filament network [Oster 1989], (3) bending elasticity of ASFs beneath the membrane [Oster 1989], and (4) contributions of viscoelasticity and tensegrity mechanisms of the CSK matrix in the cytosol [Ingber and Folkman 1989]. Because the present indentation depth mapping was performed under low-resolution force volume measurement $(4-\mu \mathrm{m}$ intervals), and because the intervals between ASFs were comparable to the order of the resolution (1-2 $\mu \mathrm{m}$; see Fig. 6), the mean indentation depths calculated for the upper nuclear and pseudopodium regions are affected considerably by the membrane positions where ASF is not located. In such positions, the indentation depths, as the representative index of cellular elasticity, reflect the contribution from the above-mentioned factors (1), (2) and (4) rather than factor (3). Based on these characteristics, stiffening of the upper nuclear region accompanied by the increased SF density and orientation is inferred to be affected not only by the increase in bending elasticity of ASFs, but also by the increase in tension in the tangential direction induced by factors (1), (2) and (4), which is proportional to the bending elasticity of the apical cell membrane [Sokabe et al. 1997]. In addition, the tension in the apical membrane is in close association with the spreading and flattening state of cell that is regulated by the size, density and manner of distribution of adhesion machineries in the basal cell membrane. Especially, factor (4) effects membrane tension through the CSK prestress change connected with the traction force change of the adhesion machineries in the basal cell membrane [Munevar et al. 
2001; Wang et al. 2001; Wang et al. 2002]. Increases in both SF density in a whole cell and ASF orientation accompanied by the stiffening of apical cell membrane observed in our result might be attributable to the effect of factor (4), together with the traction force change in the cell-substrate boundary, i.e. tensegrity mechanism. In our observation, dense SF cells were more spread out and thinner than sparse SF and sparser SF cells (Figs. 1-3). Such flattening of cells can induce a decrease in the apical membrane curvature and increase traction forces in the basal membranes, both of which can contribute to increased tension in apical membranes, thereby stiffening them.

Regarding the variance of structural features of SF, SF density has been reported to be closely associated with cell motility. Similarly to our observations, three classes of characteristic SF distribution are known: frequent or dense SF formation, a mixture of diffuse actins and SF patterns, and a lack of SF [Byers et al. 1984]. Within these classes, well-spread cells with dense SFs exhibit suppressed motility. Cells without SFs show rapid migration [Byers et al. 1984]. On the other hand, actively migrating cells show elasticity oscillation in the upper nuclear region of apical membranes and stationary cells do not exhibit such oscillation and maintain rather stiff membranes [Nagayama et al. 2001]. Increase in the SF density and the degree of orientation, suppression of motility, stiffening of apical membranes, and flattening of cells are suggested to be the events accompanying the process of cell adhesion, spreading and migration.

\section{Conclusion}

In this study, we analyzed the relationship between the elasticity of apical cell 
membranes and the structural features of actin CSKs in adhered cells, particularly emphasizing the SF density and orientation. Apical cell membranes tended to be stiffened with the increase in both SF density in a whole cell and ASF orientation as well as spreading and flattening of cells. Although further detailed study is required to clarify the mechanistic reason of such accompanying behaviors, contributions not only from the bending elasticity of ASF but also from the increase in inherent tension of apical membranes affected by such flattening and CSK prestress should be taken into account, considering the characteristics of the low resolution of the indentation depth mapping in the measurements described in this study.

\section{Acknowledgements}

This work was supported by a Grant-in-Aid for Scientific Research and for the Creation of Innovations through Business-Academic-Public Sector Cooperation from Ministry of Education, Culture, Sports, Science, and Technology (MEXT) of Japan, and supported in part by the Promotion of Fundamental Studies in Health Science of the Organization for Pharmaceutical Safety and Research (OPSR) under grant no. 97-15. 


\section{References}

Byers HR, White GE, Fujiwara K (1984) Organization and function of stress fibers in cells in vitro and in situ. Cell Muscl Motil 5: 83-137

Chang L, Kious T, Yorgancioglu M, Keller D, Pfeiffer J (1993) Cytoskeleton of living, unstained cells imaged by scanning force microscopy. Biophys J 64: 1282-1286

Dembo M, Wang YL (1999) Stresses at the cell-to-substrate interface during locomotion of fibroblasts. Biophys J 76: 2307-2316

Evans E, Yeung A (1989) Apparent viscosity and cortical tension of blood granulocytes determined by micropipette aspiration. Biophys J 56: 139-149

Folkman J, Moscona A (1978) Role of cell shape in growth control. Nature 273: 345349

Hassan EA, Heinz WF, Antonik MD, D’Costa, NP, Nageswaran S, Schoenenberger CA, Hoh J (1998) Relative microelastic mapping of living cells by atomic force microscopy. Biophys J 74: 1564-1578

Henderson E, Haydon PG, Sakaguchi DS (1992) Actin filament dynamics in living glial cells imaged by atomic force microscopy. Science 257: 1944-1946

Hertz H (1881) Ueber die Beruhrrung fester elastischer Korper. J Reine Angew Mathematik 92: 156-171

Hoh JH, Schoenenberger CA (1994) Surface morphology and mechanical properties of MDCK monolayers by atomic force microscopy. J Cell Sci 107: 1105-1114

Ingber DE, Folkman J (1989) Tension and compression as basic determinants of cell form and function: utilization of a cellular tensegrity mechanism. In Stein WD, 
Bronner F (ed.) Cell shape: Determinants, regulation, and regulatory role, Academic Press Inc., San Diego, California

Ingber DE (2003) Tensegrity I. Cell structure and hierarchical systems biology. J Cell Sci 116: $1157-1173$

Kasas S, Gotzos V, Celio MR (1993) Observation of living cells using the atomic force microscope. Biophys J 64: 539-544

Katoh K, Masuda M, Kano Y, Jinguji Y, Fujiwara K (1995) Focal adhesion proteins associated with apical stress fibers of human fibroblasts. Cell Motil Cytoskel 31: $177-195$

Katoh K, Kano Y, Masuda M, Fujiwara K (1996) Mutually exclusive distribution of the focal adhesion associated proteins and the erythrocyte membrane skeleton proteins in the human fibroblast plasma membrane undercoat. Cell Struct Funct 21: 27-39

Lo CM, Wang HB, Dembo M, Wang YL (2000) Cell movement is guided by the rigidity of the substrate. Biophys J 79: 144-152

Munevar S, Wang YL, Dembo M (2001) Traction force microscopy of migrating normal and H-ras transformed 3T3 fibroblasts. Biophys J 80: 1744-1757

Nagayama M, Haga H, Kawabata K (2001) Drastic change of local stiffness distribution correlating to cell migration in living fibroblasts. Cell Motil Cytoskeleton 50: 173179

Osborn M, Born T, Koitsch HJ, Weber K (1978) Stereo immunofluorescence microscopy: I. three-dimensional arrangement of microfilaments, microtubules and tonofilaments. Cell 14: 477-488 
Oster G (1989) Cell motility and tissue morphogenesis. Stein WD, Bronner F (ed) Cell shape: Determinants, regulation, and regulatory role. Academic Press Inc., San Diego, California

Petersen NO, McConnaughey WB, Elson EL (1982) Dependence of locally measured cellular deformability on position on the cell, temperature, and cytochalasin B. Proc. Natl. Acad. Sci. USA. 79: 5327-5331.

Pourdeyhimi B (1997) Measuring fiber orientation in nonwovens. Part III: Fourier transform. Textile Res J 67: 143-151

Rotsch C, Radmacher M (2000) Drug-induced changes of cytoskeletal structure and mechanics in fibroblasts: atomic force microscopy study. Biophys J 78: 520-535

Sneddon IN (1965) The relation between load and penetration in the axisymmetric Boussinesq problem for a punch of arbitrary profile. Int J Engng Sci 3: 47-57

Shroff SG, Saner DR, Lal R (1995) Dynamic micromechanical properties of cultured rat arterial myocytes measured by atomic force microscopy. Am. Physiol. Soc. 269: C286-C292.

Sokabe M, Naruse K, Nunogaki K (1997) Mechanosensitive ion channels: single channel vs. whole cell activities. Prog Cell Res 6: 139-149

Stein WD, Bronner F (ed) (1989) Cell shape: Determinants, regulation, and regulatory role, Chapters 8-11. Academic Press Inc., San Diego, California.

von der Mark K, Gauss V, von der Mark H, Muller P (1977) Relationship between cell shape and type of collagen synthesized as chondrocytes lose their cartilage phenotype in culture. Nature 267: 531-532 
Wang N, Bulter JP, Ingber DE (1993) Mechanotransduction across the cell surface and through the cytoskeleton. Science 20: 1124-1127

Wang N, Ingber DE (1995) Probing transmembrane mechanical coupling and cytomechanics using magnetic twisting cytometry. Biochem Cell Biol 73: 1-9

Wang, N, Naruse K, Stamenovic D, Fredberg J, Mijailovich SM, Tolic-Norrelykke IM, Polte T, Mannix R, Ingber DE (2001) Mechanical behavior in living cells consistent with the tensegrity model. Proc Natl Acad Sci USA 98: 7765-7770

Wang HB, Dembo M, Hanks SK, Wang YL (2001) Focal adhesion kinase is involved in mechanosensing during fibroblast migration. Proc Natl Acad Sci USA 98: 1129511300

Wang GN, Tolic-noprelykke IM, Chen J, Mijailovich SM, Butler JP, Fredberg JJ, Stamenovic D (2002) Cell prestress I: stiffness and prestress are closely associated adherent contractile cells. Am J Physiol Cell Physiol 282: C606-C612

White G, Fujiwara K (1986) Expression and intracellular distribution of stress fibers in aortic endothelium. J Cell Biol 103: 63-70

Wood EJ (1990) Applying Fourier and associated transforms to pattern characterization in textiles. Textile Res J 60: 212-220

Yoshinaga N, Yoshikawa K, Kidoaki S (2002) Multi-scaling in a long semi-flexible polymer chain in 2D. J Chem Phys 116: 9926-9929

Zhu C, Bao G, Wang N (2000). Cell mechanics: mechanical response, cell adhesion, and molecular deformation. Annul Rev Biomed Eng 2: 189-226 


\section{Figure Captions}

Figure 1. Typical indentation depth mapping and intracellular spatial distribution of actin CSK in cultured fibroblasts with dense SFs. (a) Phase contrast micrograph, (b) indentation depth map for the white dotted square area in (a), and (c-g) immunofluorescence images of actin CSK observed in five different focal planes. The white dotted circle in (b) shows the nuclear region. Scale bars show $10 \mu \mathrm{m}$.

Figure 2. Typical indentation depth mapping and intracellular spatial distribution of actin CSK in cultured fibroblasts with sparse SFs. (a) Phase contrast micrograph, (b) indentation depth map for the white dotted square area in (a), and (c-h) immunofluorescence image of actin CSK observed in six different focal planes. The white dotted circle in (b) shows the nuclear region. Scale bars show $10 \mu \mathrm{m}$.

Figure 3. Typical indentation depth mapping and intracellular spatial distribution of actin CSK in cultured fibroblasts with sparser SFs. (a) Phase contrast micrograph, (b) indentation depth map for the white dotted square area in (a), and (c-h) immunofluorescence image of actin CSK observed in six different focal planes. The white dotted circle in (b) shows the nuclear region. Scale bars show $10 \mu \mathrm{m}$.

Figure 4. Mean indentation depths in upper nuclear region (a) and pseudopodium region (b) of apical cell membrane, which are measured from the indentation depth maps of 20 cells. 
Figure 5. Statistical comparison of mean indentation depths in upper nuclear region and pseudopodium region of apical cell membrane from the cell groups with dense, sparse, and sparser SFs. $* p<0.001, * * p<0.005$.

Figure 6. Two-dimensional Fourier transformation analysis of distribution patterns of ASFs. Left panels: fluorescence image of typical distribution patterns of dense ASFs (a $\&$ b), coexistence of sparse ASFs and dispersed granular aggregates of actins (c \& d), and lack of ASFs (e \& f). Middle panels: Fourier-transformed power spectrum images of each distribution. Right panels: orientation distribution functions of respective Fourier-transformed images. Scale bar shows $5 \mu \mathrm{m}$.

Figure 7. Correlation between mean indentation depths on upper nuclear region of apical cell membrane and the degree of orientation of ASF evaluated from ODF. Circles, squares, and triangles respectively indicate cell groups with dense, sparse, and sparser SFs. The correlation coefficient was -0.77 . 
Figure 1

a)

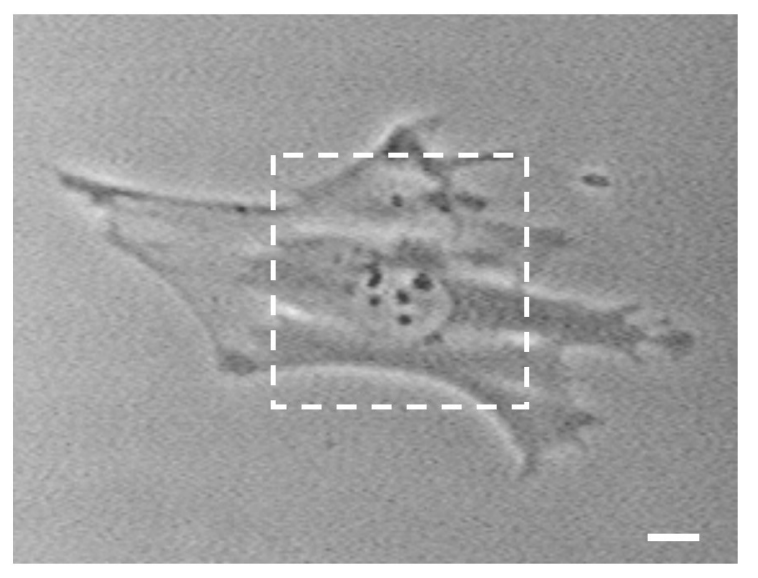

b)

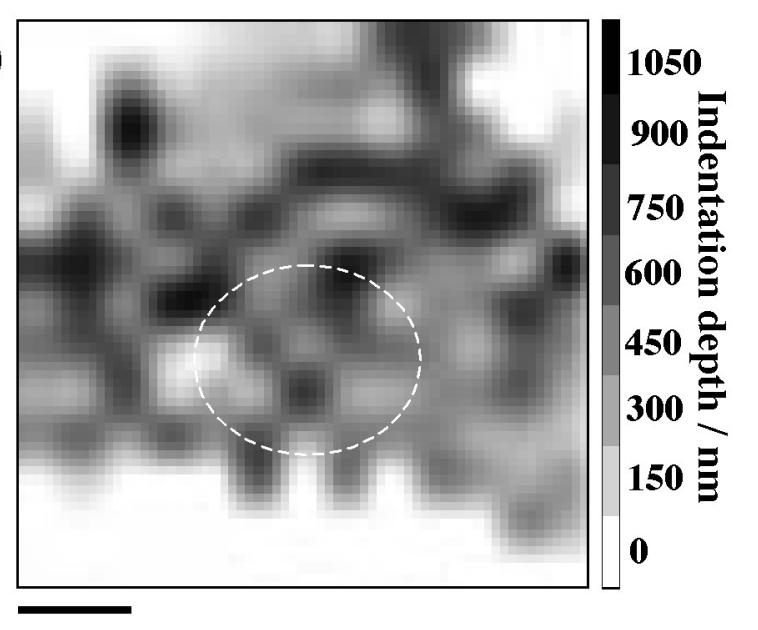

c)

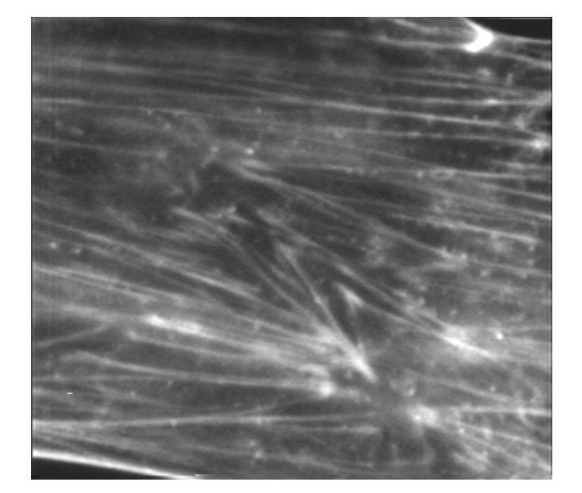

f)

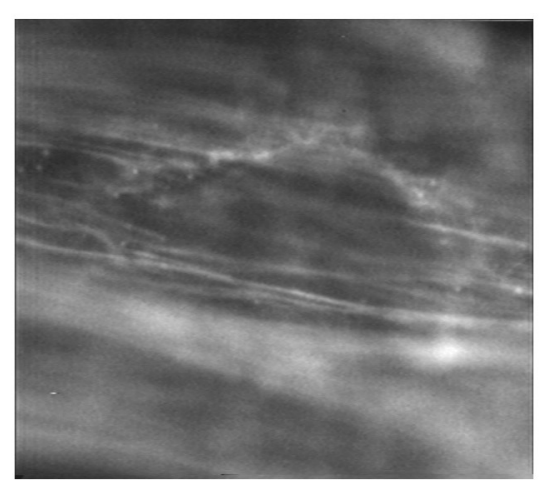

d)

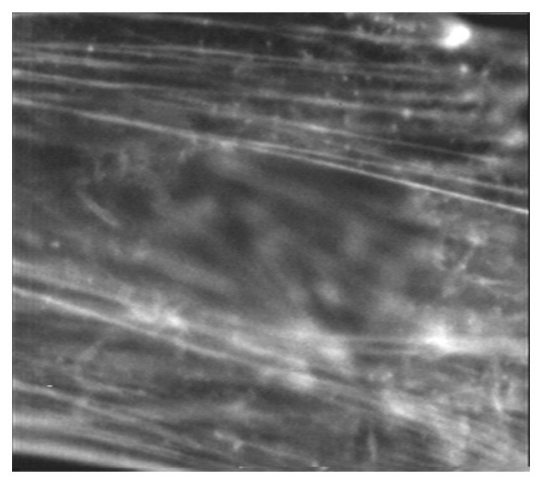

g)

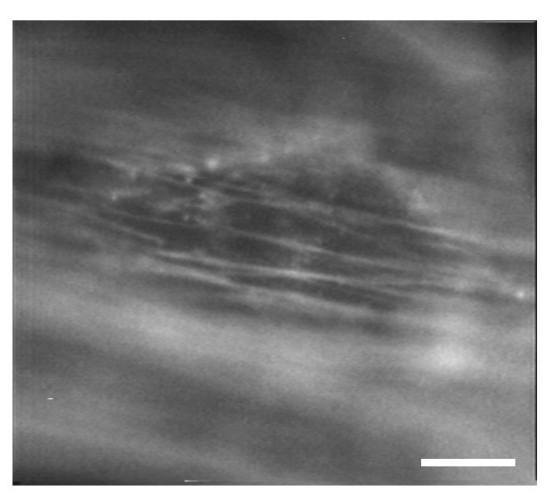

e)

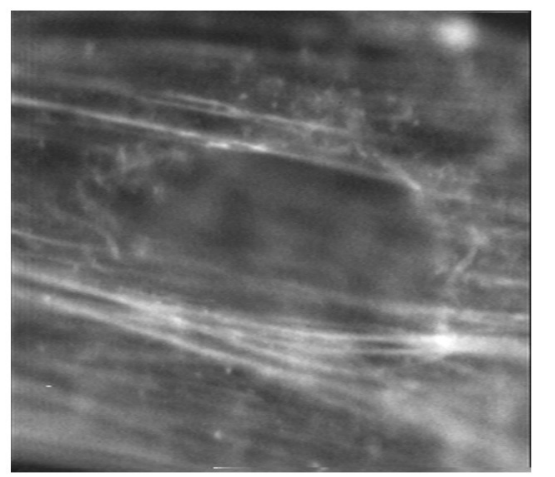


Figure 2

a)

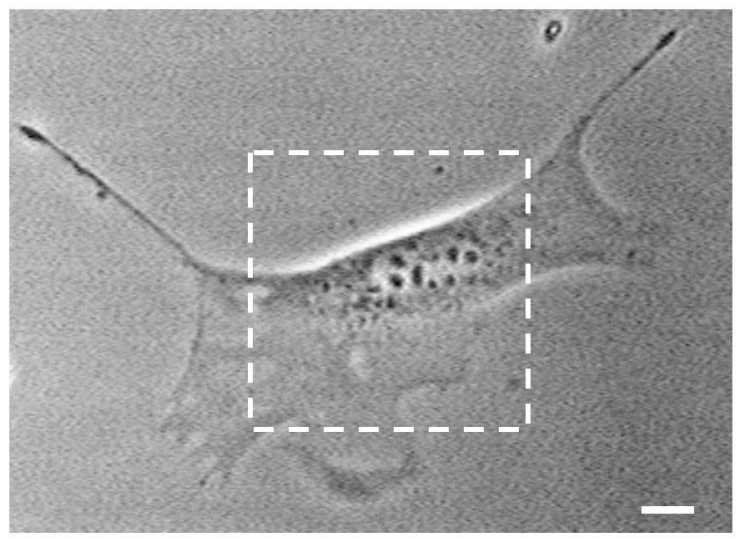

b)

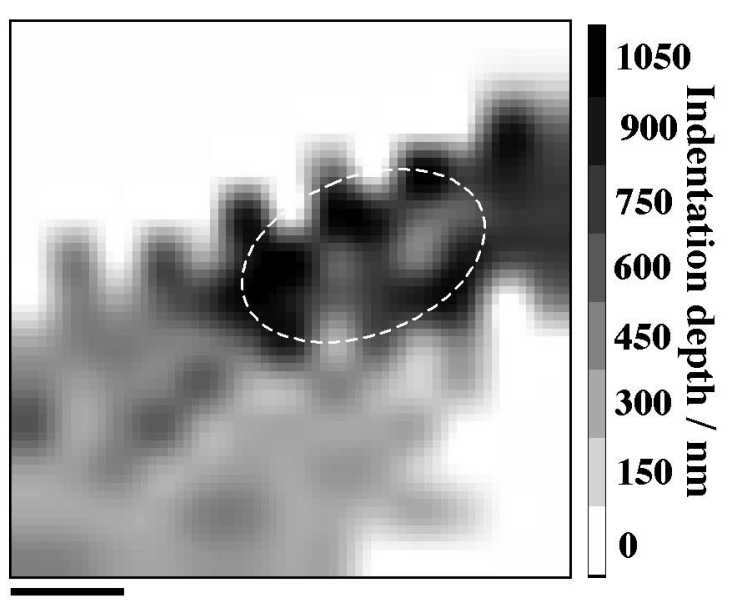

c)

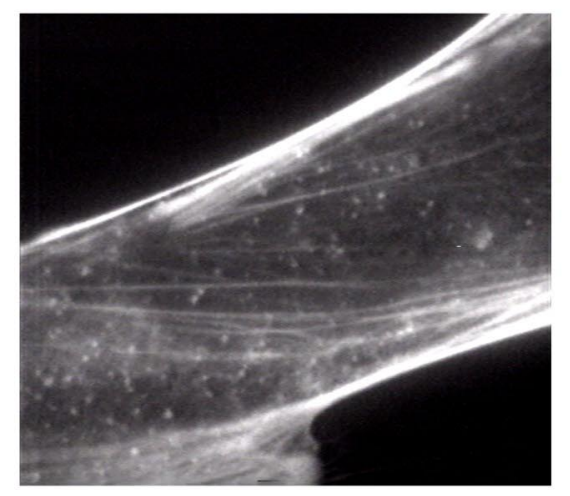

d)

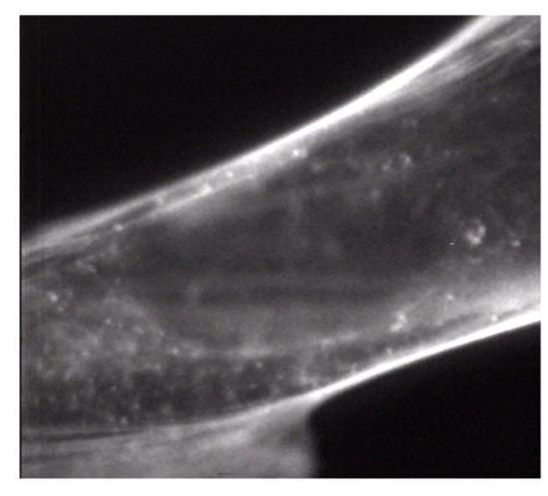

e)

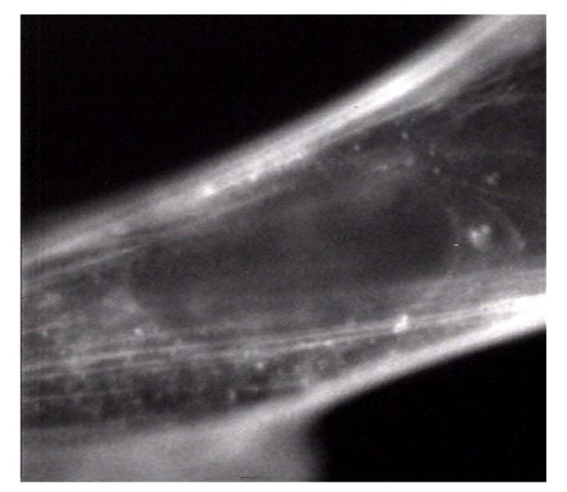

f)

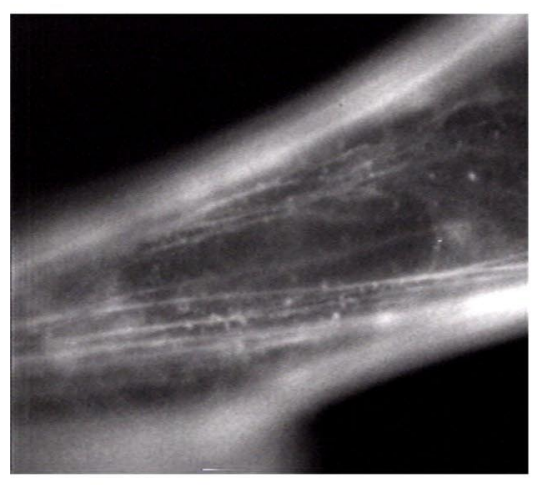

g)

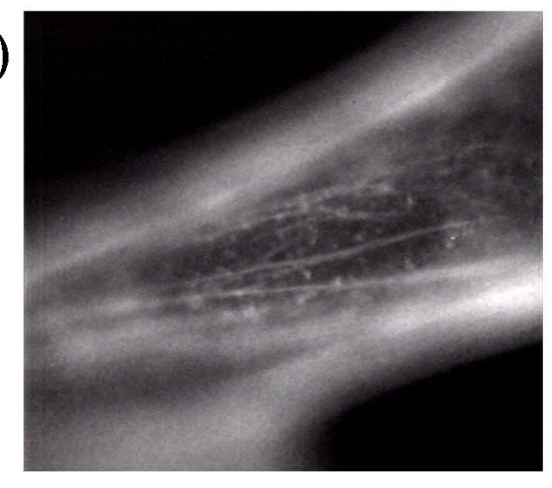

h)

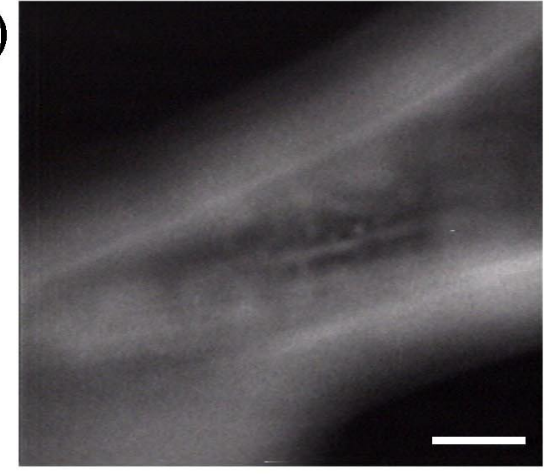


Figure 3

a)

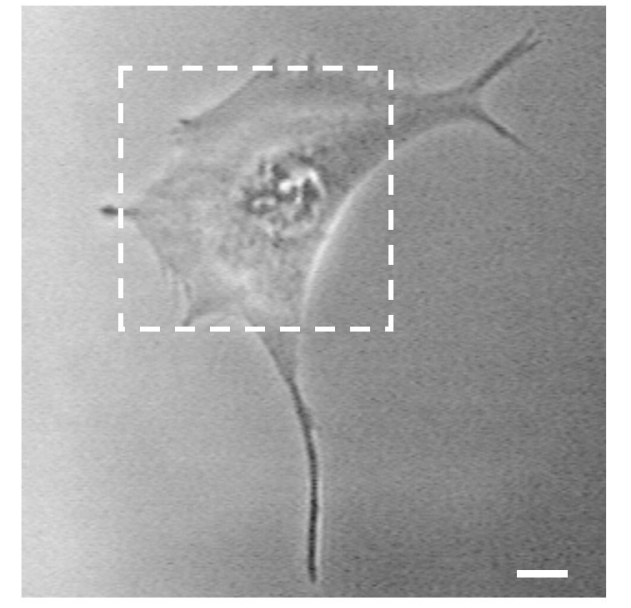

b)

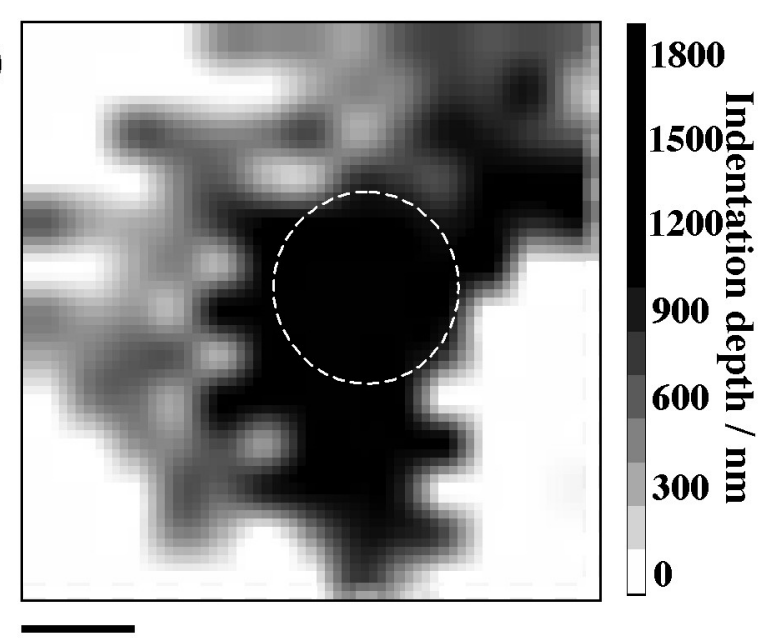

c)

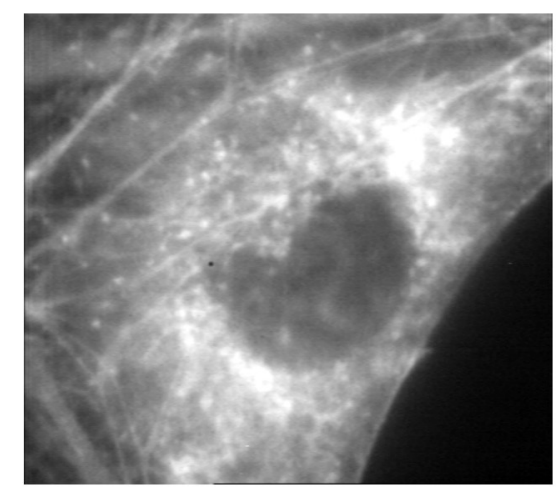

d)

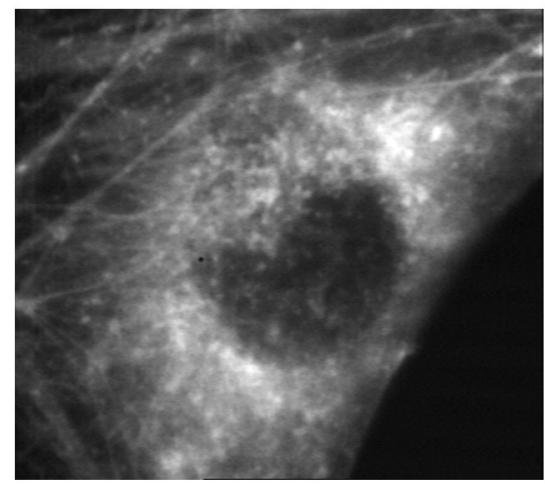

e)

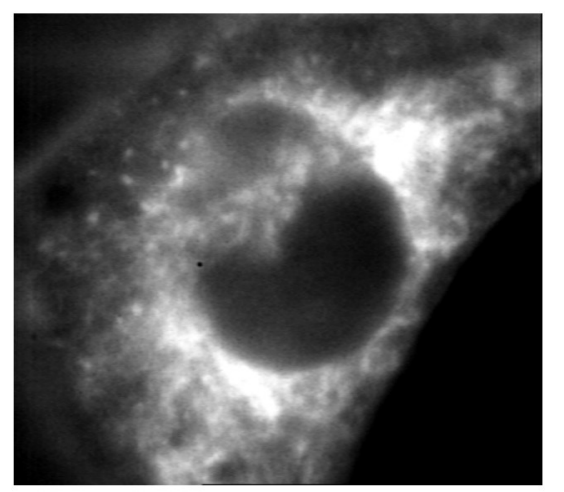

f)

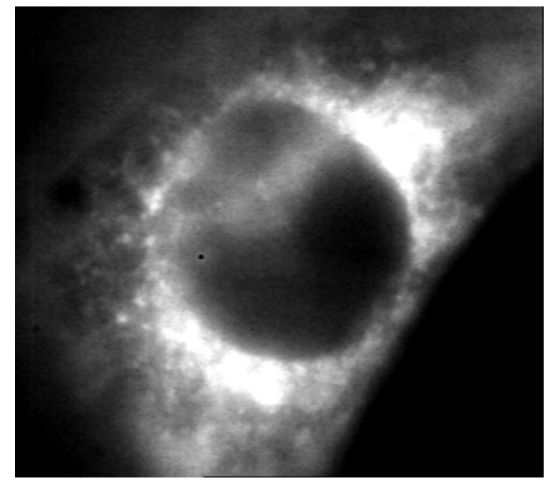

g)

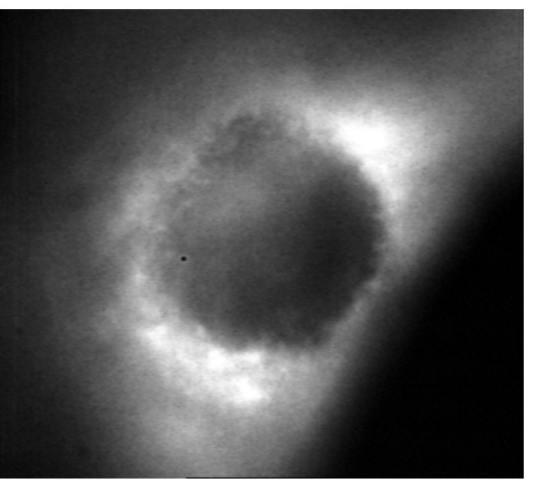

h)

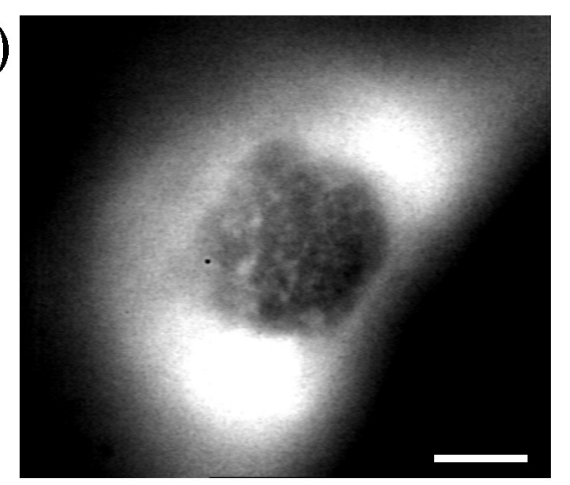




\section{Figure 4}

a) Upper nuclear region

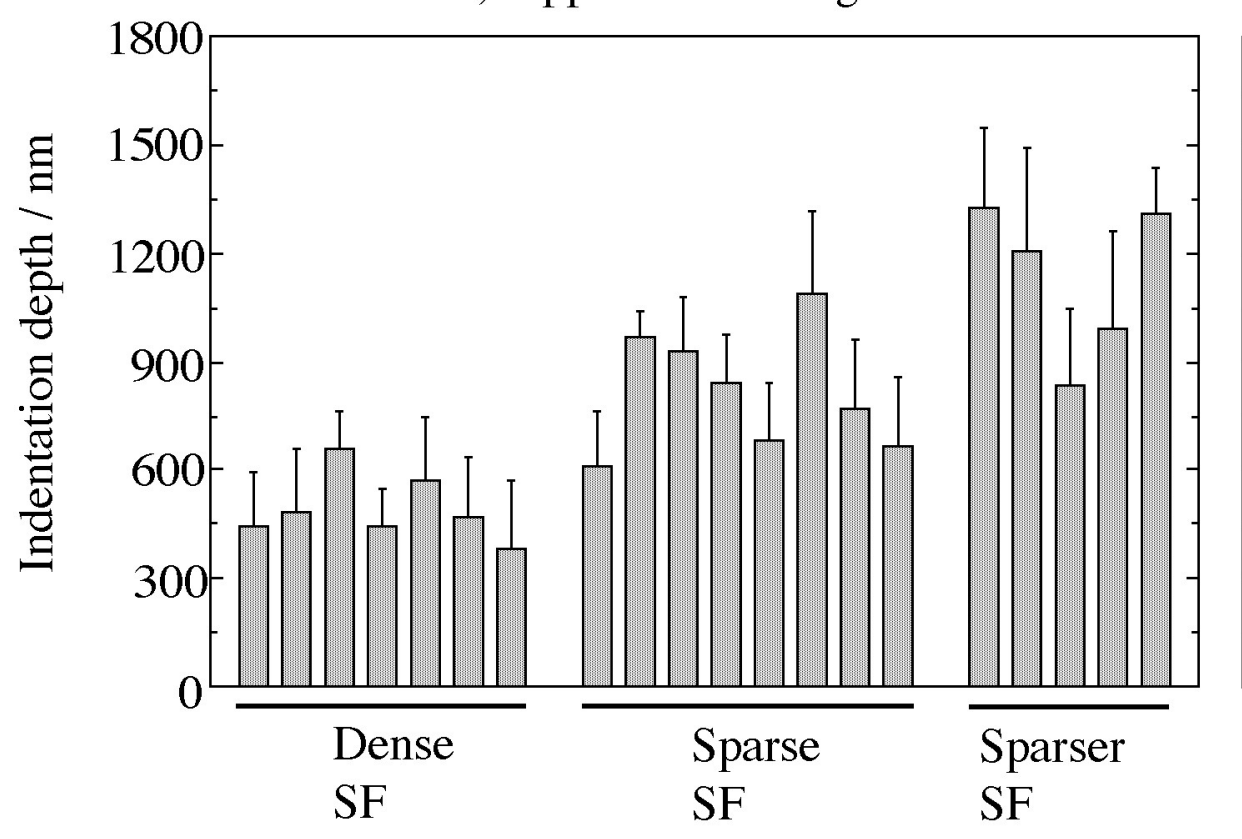

b) pseudopodium region

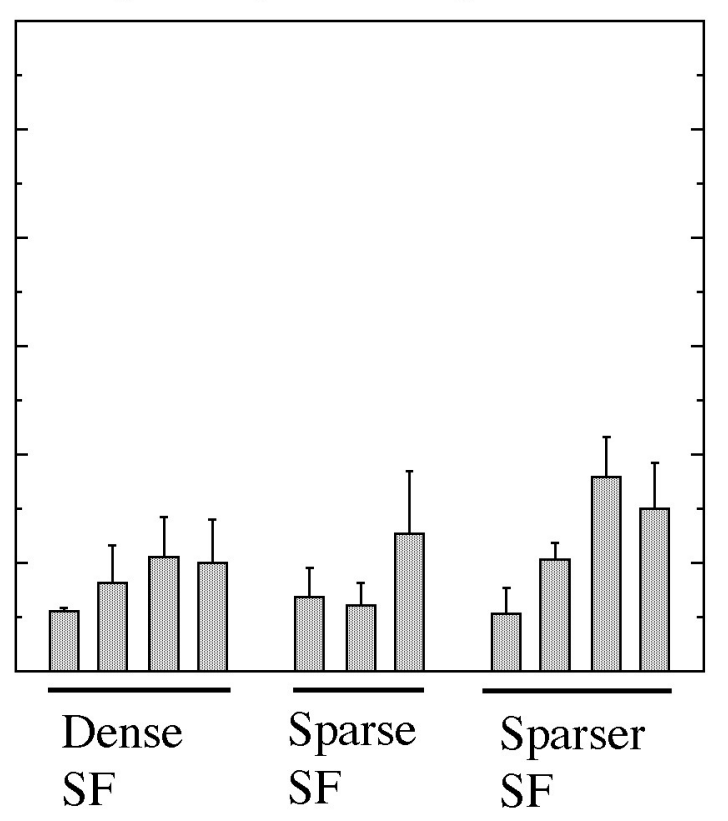


Figure 5

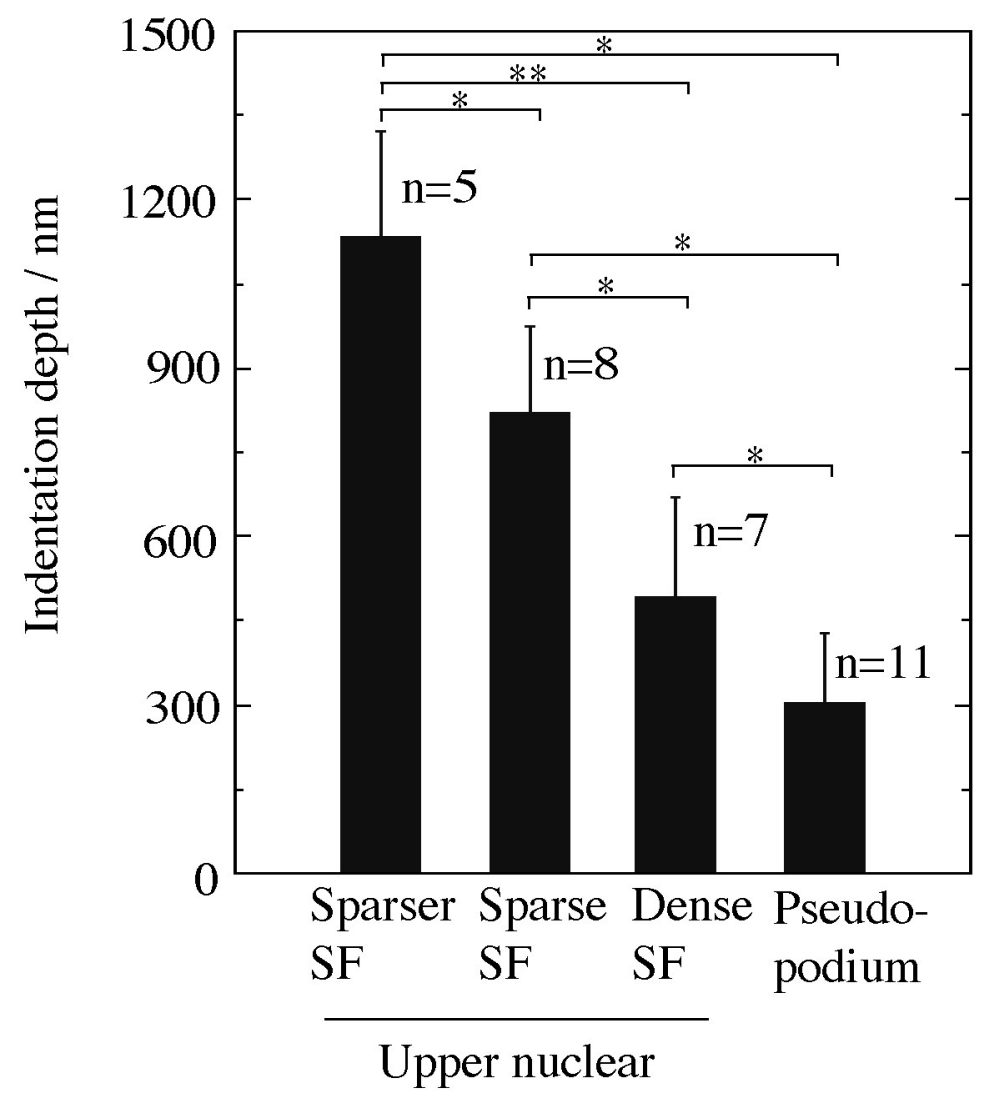




\section{Figure 6}

a)

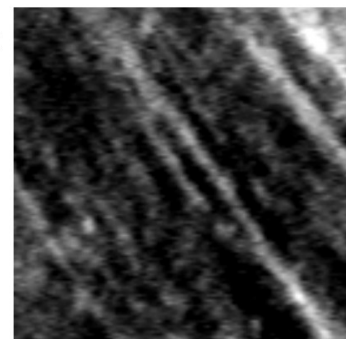

b)

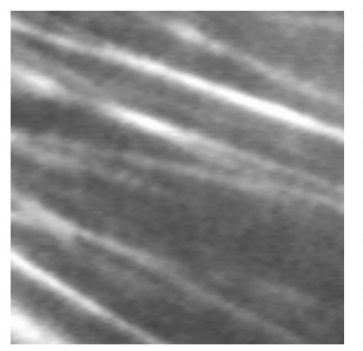

c)

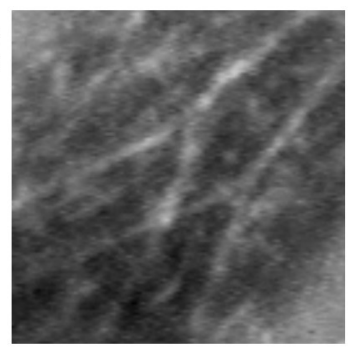

d)

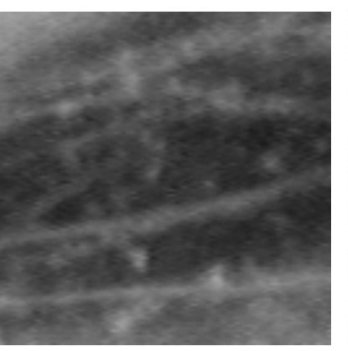

e)

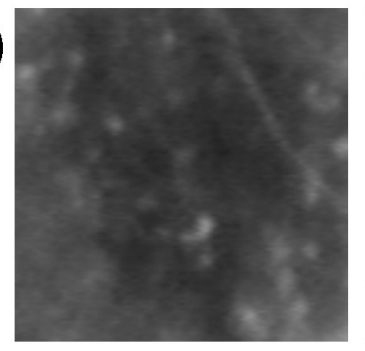

f)

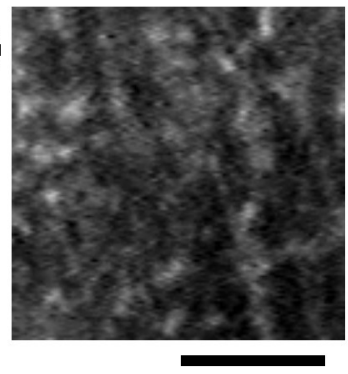

$\mathrm{P}(\theta)$
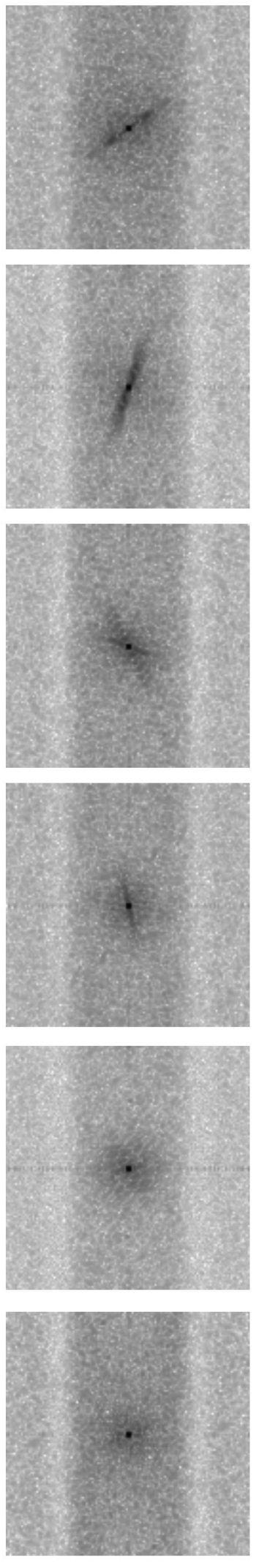

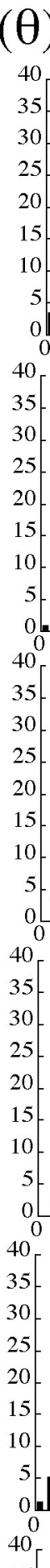

35 .

30 .

25.

15.

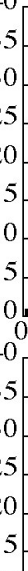
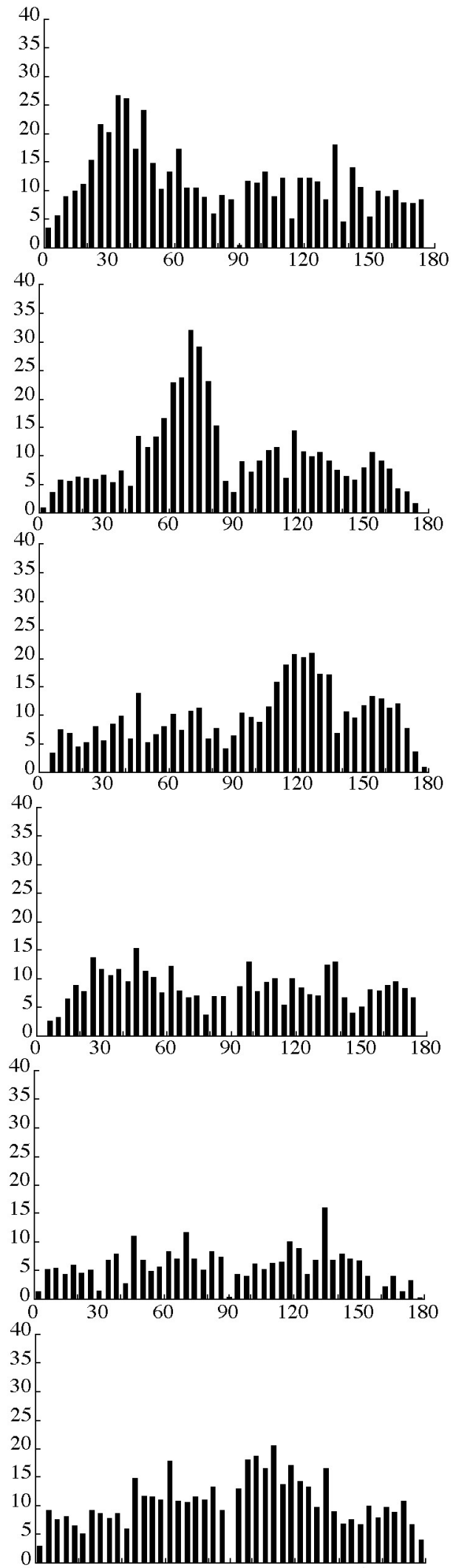

Orientation angle / degree 


\section{Figure 7}

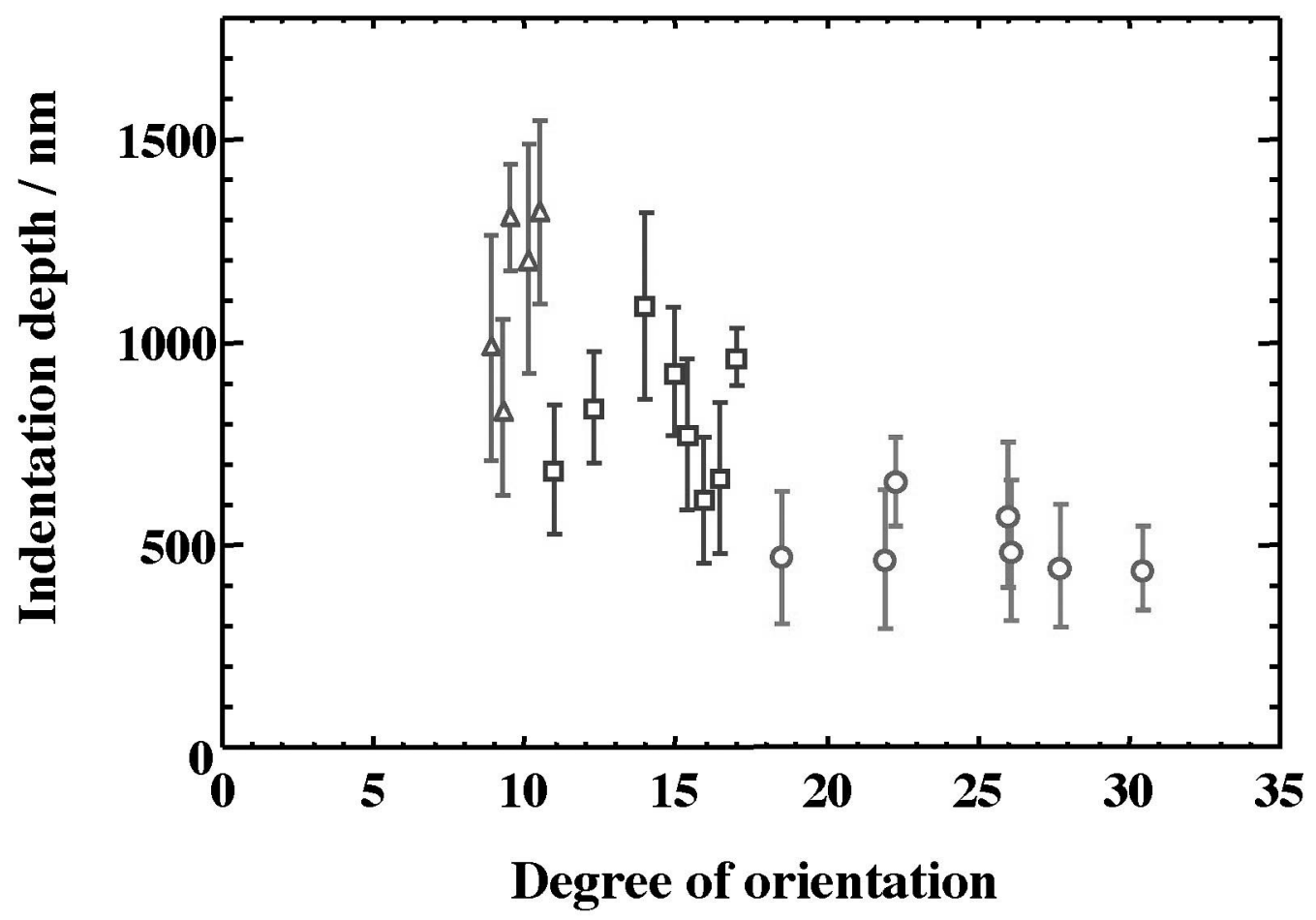

